\title{
Fueling conflict? (De)escalation and bilateral aid
}

\section{Journal Article}

Author(s):

Bluhm, Richard; Gassebner, Martin; Langlotz, Sarah; Schaudt, Paul

Publication date:

2021-03

Permanent link:

https://doi.org/10.3929/ethz-b-000475564

Rights / license:

Creative Commons Attribution 4.0 International

Originally published in:

Journal of Applied Econometrics 36(2), https://doi.org/10.1002/jae.2797 


\title{
Fueling conflict? (De)escalation and bilateral aid o
}

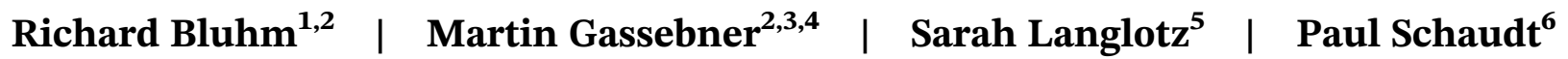

\author{
${ }^{1}$ University of California San Diego, San \\ Diego, California \\ ${ }^{2}$ Institute of Macroeconomics, Leibniz \\ University Hannover, Hannover, \\ Germany \\ ${ }^{3}$ CESifo, Munich, Germany \\ ${ }^{4}$ KOF Swiss Economic Institute, Zurich, \\ Switzerland \\ ${ }^{5}$ Department of Economics, University of \\ Göttingen, Germany \\ ${ }^{6}$ Department of Economics, University of \\ St. Gallen, St. Gallen, Switzerland

\section{Correspondence} \\ Richard Bluhm, Institute of \\ Macroeconomics, Leibniz University \\ Hannover, Königsworther Platz 1, 30167 \\ Hannover, Germany. \\ Email: bluhm@mak.uni-hannover.de
}

\begin{abstract}
Summary
This paper studies the effects of bilateral foreign aid on conflict escalation and deescalation. First, we develop a new ordinal measure capturing the two-sided and multifaceted nature of conflict. Second, we propose a dynamic ordered probit estimator that allows for unobserved heterogeneity and corrects for endogeneity. Third, we identify the causal effect of foreign aid on conflict by predicting bilateral aid flows based on electoral outcomes of donor countries which are exogenous to recipients. Receiving bilateral aid raises the chances of escalating from small conflict to armed conflict, but we find little evidence that aid ignites conflict in truly peaceful countries.
\end{abstract}

\section{1 | INTRODUCTION}

Civil conflict is not only one of the main obstacles to development, but it also tends to be concentrated in poor countries. About half of all developing countries have experienced an armed conflict in which at least 25 people died in a given year over the past four decades-directly or indirectly affecting close to four billion people. At the same time, poor and badly governed states prone to conflict need and receive substantial amounts of development assistance. Bilateral aid averaged about 5\% of recipient gross domestic product (GDP) over the same period, but does this aid appease or fuel conflict?

A large and growing literature examining this question has failed to generate a consensus. Theoretically, the relationship is ambiguous as rising opportunity costs, increasing state capacity, and greater gains from capturing the state are all plausible consequences of development assistance (e.g., Becker, 1968; Besley \& Persson, 2011a; Fearon \& Laitin, 2003). The empirical evidence is equally divided: Several studies find that aid helps (e.g., Ahmed \& Werker, 2015; de Ree \& Nillesen, 2009), while others maintain that it obstructs peace (e.g., Besley \& Persson, 2011b; Crost, Felter, \& Johnston, 2014; Dube \& Naidu, 2015; Nunn \& Qian, 2014). Devising a convincing identification strategy for bilateral aid has proven difficult given the well-known limitations of cross-country data. Credible evidence is usually limited to specific regions or countries (e.g., the Philippines, Crost et al., 2014), specific types of aid (e.g., US food aid, Nunn \& Qian, 2014), or both (e.g., US military aid in Columbia, Dube \& Naidu, 2015).

A notable divide between the theoretical and empirical literature is that the latter pays little attention to the dynamics of conflict. Empirically, conflict is usually considered to be a binary state, although recent theory stresses the importance of smaller conflicts (e.g., Bueno de Mesquita, 2013), different types of violence (e.g., Besley \&

This is an open access article under the terms of the Creative Commons Attribution License, which permits use, distribution and reproduction in any medium, provided 
Persson, 2011b), and conflict cycles (e.g., Acemoglu \& Wolitzky, 2014; Rohner, Thoenig, \& Zilibotti, 2013). Most papers distinguish between the onset and continuation of conflict, but studying these two transitions separately is an imperfect substitute for analyzing an inherently dynamic problem (N. Beck, Katz, \& Tucker, 1998). More fundamentally, there is no empirical sense of escalation or deescalation among different conflict intensities when the ordinal nature of conflict is disregarded. ${ }^{1}$ Only the case of a switch from peace to conflict and vice versa is usually accounted for. These distinctions matter. As we show in the following, small-scale conflicts below the usual minimal threshold of 25 battle-related deaths often start a cycle of violence. In contrast, in our data set, a civil war never broke out in a society that was completely at peace in the year before.

Establishing the causal effect of bilateral aid on the escalation and deescalation of conflict is the key objective of this paper. In essence, we conjecture that neglecting smaller conflicts pollutes the effect of aid on conflict. Civil discontent often first finds its expression in smaller acts of violence with comparatively low opportunity costs. Any violent behavior questions the state's monopoly of violence, satisfying what can be considered the most basic definition of civil conflict. Small conflicts thus act as a signal to the government that some part of society is not content with the current provision, or division, of public goods. In addition, they help potential rebels to get an estimate of how easily they can overcome collective action problems and provide information about the government's repressive capabilities. Foreign aid, in turn, may exacerbate violent tendencies in such environments but not when society is truly at peace.

Our empirical analysis introduces three novelties in order to identify these dynamics. First, we propose a new measure of conflict which captures the gradations of civil violence from peace over intermediate categories to fully fledged civil wars. Second, we develop a dynamic ordered probit framework which allows us to estimate escalation and deescalation probabilities for multiple states. In our approach, the onset, continuation, and the duration of each realization of civil violence are all well defined. We then extend this basic framework to account for unobserved heterogeneity (quasi fixed effects) and correct for the endogeneity of aid (based on Giles \& Murtazashvili, 2013; Rivers \& Vuong, 1988; Wooldridge, 2005a). Third, and most importantly, we identify the effect of aid on conflict using characteristics of the electoral system of donor countries. We interact political fractionalization of each donor with the probability of receiving aid to predict bilateral aid flows in a "gravity style" aid equation (Dreher \& Langlotz, 2020; Frankel \& Romer, 1999). This type of identification strategy is commonly used in the trade and migration literatures but usually relies on structural characteristics of both partner countries. We solely use the variation arising from electoral outcomes in donor countries combined with the likelihood of receiving aid.

The simultaneity of aid and conflict makes causal identification notoriously difficult. The strong correlation of low GDP per capita and civil strife is one of the most robust findings in the literature (e.g., Blattman \& Miguel, 2010; Fearon \& Laitin, 2003). Underdevelopment, in turn, is the chief motivation to provide development aid (see, e.g., Brückner, 2013). As a result, the effect of aid is likely to be biased upwards if aid is primarily given to countries in need, or biased downwards if donors are driven by political motives or reduce aid in light of the logistical challenges created by conflict. To address this endogeneity Nunn and Qian (2014) use lags of US wheat production interacted with each recipient's frequency of receiving aid as an instrument for US food aid. Our approach extends the spirit of their identification strategy to all major bilateral donors, with the explicit aim of drawing conclusions that go beyond the (limited) effects of food aid given by one large donor. ${ }^{2}$

Our main results show that the causal effect of foreign aid on the various transition probabilities is heterogeneous and, in some instances, sizable. Foreign aid has a different effect on the probability of experiencing conflict, depending on whether a society was entirely peaceful, already in turmoil, or mired in major civil conflict. Aid does not seem to harm recipient countries by causing conflict across the board. While all estimates suggest that bilateral aid tends to fuel conflict, we find little evidence suggesting that foreign aid leads to new eruptions of conflict or that it drives the escalation towards (or the continuation of) civil wars. At face value, the positive signs are also at odds with the notion that opportunity costs rise with more development assistance, although it remains difficult to delineate the exact channels.

Our findings suggest that aid can be harmful when given to countries already experiencing violent turmoil just short of the conventional definition of civil conflict. In those cases we find (i) a strong negative effect on the probability of transitioning back to peace, (ii) an elevated risk of continued violence, and (iii) a nontrivial probability of escalating into armed conflict. Donor countries have to be aware of the unintended consequences of giving aid to countries with lingering conflicts.

\footnotetext{
${ }^{1}$ Besley and Persson (2011a) are closest to our approach in the sense that they use ordered outcome models, but do not account for conflict histories, history-dependent effects, or persistence.

${ }^{2}$ Much of the groundwork has been done in Dreher and Langlotz (2020), who first introduced political fractionalization interacted with the probability of receiving aid as an instrument for bilateral aid flows in the context of growth regressions.
} 
Our results underscore the importance of carefully modeling the dynamics of conflict. This echoes the recent literature (e.g., Bazzi \& Blattman, 2014; Berman \& Couttenier, 2015; Nunn \& Qian, 2014) but our analysis goes several steps further and generates new insights. Escalation or deescalation-that is, the switching among different conflict intensities-is a dynamic process and the established binary peace-war typology hides important heterogeneity. What is often coded as peace is not actually peaceful and what influences the decision to fight differs in these situations.

The remainder of the paper is organized as follows. Section 2 introduces our new ordinal conflict measure. Section 3 outlines our empirical model and identification strategy. Section 4 presents the empirical results and several extensions. Section 5 concludes.

\section{2 | DATA}

We study the occurrence of civil violence in 125 developing countries over the period from 1975 to 2010 . A list of the included countries and summary statistics of all variables can be found in Section A of the online Supporting Information.

\section{$2.1 \quad$ An ordinal measure of conflict}

A distinct feature of the civil conflict literature is its crude measurement of conflict. The industry standard is to first count the number of battle-related deaths (BDs) and then to create dummy variables indicating the surpassing of one of two thresholds (25 or 1,000 BDs) for the first time (conflict onset) or for any given year other than the first (continuation or ending). Clearly, a key concern motivating this choice is noise in the underlying raw data and theoretical ambiguity about what constitutes "conflict."

We propose a new ordinal measure of conflict with four states. For comparability, we begin with the standard UCDP-PRIO measure of civil conflict (Gleditsch, Wallensteen, Eriksson, Sollenberg, \& Strand, 2002). UCDP-PRIO defines civil conflict as a contested incompatibility that concerns the government or a territory in which armed force between two parties, one of which is the government, results in at least 25 BDs per annum. We call conflicts that reach this state but do not exceed 1,000 BDs in a given year "armed conflict." At the top, we add a category called "civil war" if there are more than 1,000 BDs. At the bottom, we create the category "small conflict" using data from the Databanks International's Cross-National Time-Series Data Archive (CNTS) on government purges, assassinations, riots, and guerrilla warfare (Banks \& Wilson, 2015). ${ }^{3}$ Small conflicts are an integral part of rebel tactics for several reasons: (i) they help to overcome collective action and information problems; (ii) they have smaller opportunity costs; and (iii) they can be strategic substitutes to conventional warfare in a long-standing rebellion (Bueno de Mesquita, 2013).

All of these categories are manifestations of civil conflict, albeit on a lower intensity level. The UCDP-PRIO data are generally considered to be more rigorously constructed than the CTNS data but do not report low-intensity events. We solely use the CNTS data to identify whether there has been any violence below the 25 BDs threshold of armed conflict. We include observations of the CNTS data that are comparable to the type of conflict we consider in the above categories-that is, conflicts between two parties, one being the state (two-sided, state-centered). ${ }^{4}$ Only a society without any event is assigned to the category "peace." As a whole, the countries in our sample spend about one third of all years in conflict at various intensities and about two thirds of all years in peace (see Figure 1).

A key advantage of our approach is that the number of armed conflicts and civil wars in our sample are identical to the UCDP-PRIO measure. Hence our results are comparable with existing studies and differ mainly due to the definition of peace. We distinguish between truly peaceful observations and those with irregular violence below the conventional thresholds. This conservative approach of changing existing measures implies that our ordinal measure can be easily compared to the industry standard and its interpretation is straightforward. We avoid weighting procedures such

\footnotetext{
${ }^{3}$ The precise definitions of our variables from the CNTS User's Manual are as follows. Purges: Any systematic elimination by jailing or execution of political opposition within the ranks of the regime or the opposition. Assassinations: Any politically motivated murder or attempted murder of a high government official or politician. Riots: Any violent demonstration or clash of more than 100 citizens involving the use of physical force. Guerrilla Warfare: Any armed activity, sabotage, or bombings carried on by independent bands of citizens or irregular forces and aimed at the overthrow of the present regime.

${ }^{4}$ In the case of riots this may not be obvious from the variable definition, but the large riots recorded in the CNTS data usually involve violent clashes between anti-government protesters with (pro-)government forces. They are what incumbents react to with repression. For a prototypical example, see Yemen in 2011 (https://www.nytimes.com/2011/02/15/world/middleeast/15yemen.html).
} 
F I G U RE 1 Distribution of conflict intensities. The figure presents an illustration of the unconditional distribution of the ordinal conflict measure. There are 3,014 peace years, 739 small conflict years, 544 armed conflict years, and 203 civil war years in our sample

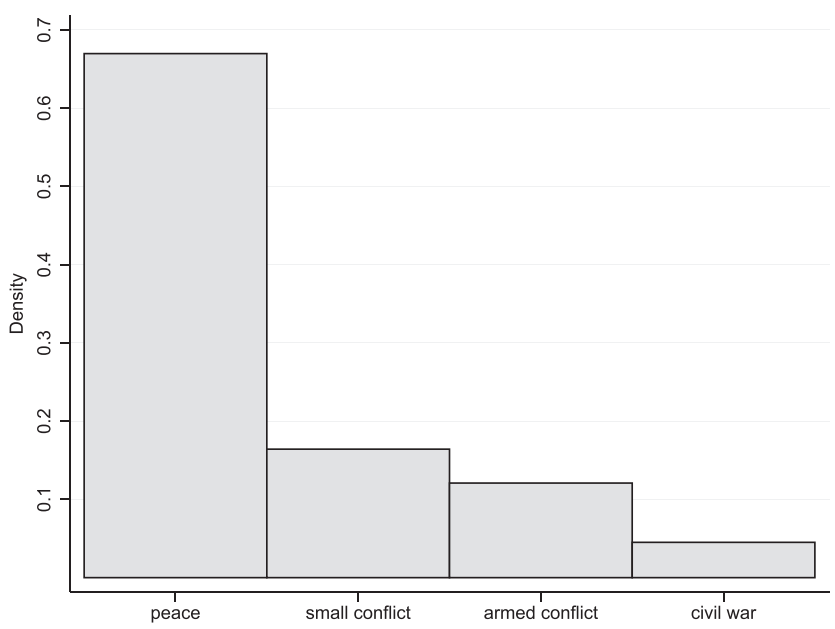

TABLE 1 Unconditional transition matrix (in \%)

\begin{tabular}{llllr} 
& \multicolumn{2}{l}{ To state } & & \\
\cline { 2 - 6 } From state & Peace & Small conflict & Armed conflict & Civil war \\
\hline Peace & 87.26 & 10.69 & 2.06 & 0.00 \\
Small conflict & 43.85 & 48.13 & 6.78 & 1.24 \\
Armed conflict & 11.28 & 8.46 & 70.30 & 9.96 \\
Civil war & 1.49 & 5.97 & 23.88 & 68.66 \\
\hline
\end{tabular}

Note. The table reports the raw transition matrix estimated using the same balanced sample of 125 countries over 36 years that is used in the main analysis (4,500 observations imply 4,375 transitions). Rows sum to $100 \%$.

as those used by the composite index of the CNTS data set. We also deliberately refrain from mixing flow and stock variables to measure different conflict intensities, such as taking the cumulative amount of BDs to create intermediate levels of armed civil conflict (e.g., Bazzi \& Blattman, 2014; Esteban, Mayoral, \& Ray, 2012). Measures including both flow and stock variables do not allow us to study escalation and deescalation since they have absorbing terminal states. The Supporting Information presents the case of the Sri Lankan civil war to illustrate the benefits of our coding in more detail.

Table 1 shows the unconditional transition probabilities as they are observed in our data. This simple exercise already allows us to make three worthwhile points. First, the cyclical nature of conflicts is clearly visible but there is not a single country in our data set where peace immediately preceded civil war. Second, our coding of small conflict achieves a credible and important separation of the lower category. Peace is now very persistent and, if anything, a transition to a small conflict is most likely. Small conflict is a fragile state which often reverts back to peace, is not particularly persistent, but does sometimes erupt into more violent states. Third, higher intensity conflicts are once again more persistent. These observations match up well with the literature-in particular, the use of irregular means to increase mobilization for a future conventional campaign and increased persistence as outside opportunities erode (Bueno de Mesquita, 2013).

\section{2 | Bilateral aid flows and controls}

Our main independent variable is official development aid (ODA) disbursed by 28 bilateral donors of the OECD Development Assistance Committee (DAC). ODA refers to flows that are (i) provided by official agencies to developing countries and multilateral institutions, (ii) have economic development and welfare as their main objective, and (iii) have a concessional character. The last condition reflects that the grant element should be at least $25 \% .{ }^{5}$ We use net

${ }^{5}$ Other official flows (OOF) include flows by the official sector with a grant element of less than $25 \%$ or flows that are not primarily aimed at development. Table D-4 in the Supporting Information presents results based on these flows. 
ODA flows which include loan repayments since these reduce the available funds. In the Supporting Information, we also consider multilateral aid. All flows are normalized by GDP.

The data for government and legislative fractionalization (in donor countries) are from T. Beck, Clarke, Groff, Keefer, and Walsh (2001). For the set of core controls, we include the log of population (from the World Development Indicators) to capture the scale effect inherent in conflict incidence and the log of GDP (from the Penn World Table 7.1).

\section{3 | EMPIRICAL STRATEGY}

\section{1 | Conflict histories}

Dynamic switches among multiple states cannot be meaningfully estimated with linear models. N. Beck et al. (1998) show that separately specifying models of onset and ending of war is equivalent to a dynamic model of war incidence. However, many more linear models would be needed to study the transition among multiple states. The result would be unstable parameter estimates that are inefficiently estimated, potentially biased, and difficult to interpret. Further, if we believe that there is an underlying latent variable ("conflict") which is observed as an ordered outcome, then separate regressions can violate known parameter restrictions. ${ }^{6}$ Hence a nonlinear framework is needed.

Some notation will help to fix ideas. As typical in an ordered setting, we observe a conflict outcome $c_{i t}$ which takes on $J+1$ different values in country $i$ at time $t$. A specific outcome is $j \in\{0,1, \ldots, J\}$. The outcomes are ordered by intensity (i.e., peace, small conflict, armed conflict, civil war) and are generated by a continuous latent variable $c_{i t}^{*}$ with $J$ cut points $\alpha_{1}<\ldots<\alpha_{j}<\ldots<\alpha_{J}$ to be estimated later. The first outcome is $c_{i t}=0$ if $-\infty<c_{i t}^{*} \leq \alpha_{1}$, the intermediate outcomes are $c_{i t}=j$ if $\alpha_{j}<c_{i t}^{*} \leq \alpha_{j+1}$ with $0<j<J$, and the last outcome is $c_{i t}=J$ if $\alpha_{J}<c_{i t}^{*}<\infty$.

Next, define the associated $J \times 1$ vector of one period conflict histories as $\mathbf{h}_{i, t-1} \equiv\left(h_{1, i, t-1}, \ldots, h_{j, i, t-1}, \ldots, h_{J, i, t-1}\right)^{\prime}$. The typical element of $\mathbf{h}_{i, t-1}$ is $h_{j, i, t-1} \equiv 1\left[c_{i, t-1}=j\right]$ 一that is, an indicator of whether the past outcome is identical to outcome $j$.

Contrary to the standard approach, our latent variable model of interest has a full set of history dependent effects:

$$
c_{i t}^{*}=\mathbf{x}_{i t}^{\prime} \beta+\mathbf{h}_{i, t-1}^{\prime} \rho+\left(\mathbf{x}_{i t} \otimes \mathbf{h}_{i, t-1}\right)^{\prime} \gamma+\mu_{i}+\varepsilon_{i t},
$$

where $\mathbf{x}_{i t}$ is a column vector of regressors without a constant, $\mathbf{h}_{i, t-1}$ is defined above, and the Kronecker product simply accounts for all possible interactions between $\mathbf{x}_{i t}$ and $\mathbf{h}_{i, t-1}$. We include country-level unobserved effects, $\mu_{i}$, whose identification we discuss below. Typically we will partition the vector $\mathbf{x}_{i t}=\left(\mathbf{x}_{\mathbf{1}_{i t}^{\prime}}^{\prime}, \mathbf{x}_{\mathbf{2}_{i t}^{\prime}}^{\prime}\right)^{\prime}$, so that some variables are history dependent and others are not (e.g., proxy controls and time dummies). We are only interested in the estimated coefficients insofar as they define the relevant probabilities.

Conditional on the covariates and the conflict history we have three different types of outcome probabilities: $\operatorname{Pr}\left[c_{i t}=0 \mid \mathbf{x}_{i t}, \mathbf{h}_{i, t-1}\right]=\operatorname{Pr}\left[c_{i t}^{*} \leq \alpha_{1} \mid \mathbf{x}_{i t}, \mathbf{h}_{i, t-1}\right], \operatorname{Pr}\left[c_{i t}=j \mid \mathbf{x}_{i t}, \mathbf{h}_{i, t-1}\right]=\operatorname{Pr}\left[\alpha_{j}<c_{i t}^{*} \leq \alpha_{j+1} \mid \mathbf{x}_{i t}, \mathbf{h}_{i, t-1}\right], \quad$ and $\quad \operatorname{Pr}\left[c_{i t}=J \mid \mathbf{x}_{i t}, \mathbf{h}_{i, t-1}\right]=$ $\operatorname{Pr}\left[c_{i t}^{*}>\alpha_{J} \mid \mathbf{x}_{i t}, \mathbf{h}_{i, t-1}\right]$. We have to be more explicit in the notation since we are interested in the transition and continuation probabilities of the various states. For simplicity, just focus on the $j$ th intermediate outcome where $0<j<J-1$, then without loss of generality we can define continuation, escalation, and deescalation from an initial state $j+p$ to outcome $j$ as

$$
\begin{aligned}
\operatorname{Pr}\left[c_{i t}=j \mid \mathbf{x}_{i t}, h_{j+p, i, t-1}=1\right]= & F\left[\alpha_{j+1}-\mathbf{x}_{i t}^{\prime} \beta-\rho_{j+p}-\left(\mathbf{x}_{i t} \times h_{j+p, i, t-1}\right)^{\prime} \gamma_{j+p}-\mu_{i}\right] \\
& -F\left[\alpha_{j}-\mathbf{x}_{i t}^{\prime} \beta-\rho_{j+p}-\left(\mathbf{x}_{i t} \times h_{j+p, i, t-1}\right)^{\prime} \gamma_{j+p}-\mu_{i}\right],
\end{aligned}
$$

where we have escalation if $p<0$, continuation if $p=0$, and deescalation if $p>0$. The case of $p=0$ is often also called "persistence." $F(\cdot)$ is some continuous symmetric cumulative distribution function which is defined by the distribution of the error terms, $\varepsilon_{i t}$.

${ }^{6}$ This is a version of the misnamed "parallel regression assumption" in ordered probit models. If the outcome is an ordered response, then the predicted probabilities of falling below a certain cut point must be increasing in the outcome $j$ for all values of the covariates (Wooldridge, 2010, p. 658). If all the coefficients can vary in each state, then this meaningless result cannot be ruled out. 
The purpose of this entire exercise is to be able to define the partial effect of a particular $x_{k, i t} \in \mathbf{x}_{i t}$ on one of the transition probabilities defined above. It should now be straightforward to see that these are the derivatives of a particular probability with respect to $x_{k, i t}$. For example, in the case of continuing in the past state $j$ we have

$$
\begin{aligned}
\frac{\partial}{\partial x_{k}}\left(\operatorname{Pr}\left[c_{i t}=j \mid \mathbf{x}_{i t}, h_{j, i, t-1}=1\right]\right)= & \left(\beta_{k}+\gamma_{j, k}\right)\left\{f\left[\alpha_{j}-\mathbf{x}_{i t}^{\prime} \beta-\rho_{j}-\left(\mathbf{x}_{i t} \times h_{j, i, t-1}\right)^{\prime} \gamma_{j}-\mu_{i}\right]\right. \\
& \left.-f\left[\alpha_{j+1}-\mathbf{x}_{i t}^{\prime} \beta-\rho_{j}-\left(\mathbf{x}_{i t} \times h_{j, i, t-1}\right)^{\prime} \gamma_{j}-\mu_{i}\right]\right\},
\end{aligned}
$$

where $f(\cdot)$ is the probability density function of $F(\cdot)$.

We still lack a formal definition of state dependence. In binary models, state dependence is the probability of an event happening when the event happened before minus the probability of the event when it did not happen before net of all other observed and unobserved factors. With ordered outcomes it is no longer that simple. We need to account for the fact that there are several ways of entering into a particular state. Following Cappellari and Jenkins (2004), we estimate state dependence as the difference between experiencing a particular state if it has occurred before and a weighted average of the ways of entering this state when it has not occurred before.

Formally, define state dependence in state $j$ as follows:

$$
S_{j}=(N T)^{-1} \sum_{i}^{N} \sum_{t}^{T}\left(\operatorname{Pr}\left[c_{i t}=j \mid \mathbf{x}_{i t}, h_{j, i, t-1}=1\right]-\sum_{r \neq j} \omega_{r j} \operatorname{Pr}\left[c_{i t}=j \mid \mathbf{x}_{i t}, h_{r, i, t-1}=1\right]\right),
$$

where the weights, $\omega_{r j}$, are the normalized class frequencies (the number of observations that can potentially make the switch, normalized to sum to unity). We expect state dependence to increase with higher conflict intensities. The higher the level of conflict, the more difficult it becomes to leave states that have a destructive nature, whereas peace should also be self-reinforcing.

\section{2 | Dynamic ordered probit with endogeneity}

Identification of endogenous regressors and their partial effects under the presence of heterogeneity and first-order dynamics is not trivial in nonlinear settings. Researchers often opt for linear instrumental variable methods to keep things simple, but here we trade simplicity for a better understanding of the dynamics.

To model the ordered conflict outcome, we combine correlated random effects (CRE) and a control function (CF) approach with dynamic panel ordered probit models. Dynamic models with correlated random effects where all regressors are strictly exogenous have been studied by Wooldridge (2005a), among others, and endogeneity was introduced into these types of dynamic binary choice models by Giles and Murtazashvili (2013). To the best of our knowledge, we are the first to employ a CRE approach with an endogenous regressor in a dynamic ordered setting. A noteworthy limitation of this approach is that it does not work with unbalanced panels.

We incorporate two specific features into the general formulation considered above. First, we consider an endogenous regressor (the ratio of bilateral aid to GDP) and, second, we interact this variable with the one period conflict history. We do not include other interactions with the lagged states. Hence our model of interest becomes

$$
c_{1 i t}^{*}=\mathbf{z}_{1 i t}^{\prime} \beta_{1}+\beta_{2} a_{2 i t}+\mathbf{h}_{1 i, t-1}^{\prime} \rho+\left(a_{2 i t} \times \mathbf{h}_{1 i, t-1}\right)^{\prime} \gamma+\mu_{1 i}+\lambda_{1 t}+u_{1 i t},
$$

where $\mathbf{z}_{1 i t}$ is a column vector of strictly exogenous variables, $a_{2 i t}$ is the endogenous aid to GDP ratio, $\lambda_{1 t}$ are time dummies, and everything else is defined as before. We added subscripts to each variable or vector if they belong to the main equation of interest (1) or the reduced form (2). We assume that the model is dynamically complete once the firstorder dynamics are accounted for and that the error term is free of serial correlation. We relax this assumption later when we discuss extensions to the model. The process starts at $s<0$ and is observed over $t=0, \ldots, T$. We always lose the first period, so in Equation 5 and from now on estimation runs over $t=1, \ldots, T$.

The endogenous aid to GDP ratio has the following linear reduced form: 


$$
a_{2 i t}=\mathbf{z}_{1 i t}^{\prime} \alpha_{1}+\mathbf{z}_{2 i t}^{\prime} \alpha_{2}+\mu_{2 i}+\lambda_{2 t}+u_{2 i t},
$$

where $\mathbf{z}_{2 i t}$ is a vector of instruments that is relevant and excluded from the main equation. Our instrument is generated from bilateral regressions. We discuss its construction in detail in the next subsection.

We assume that the reduced-form heterogeneity can be expressed as $\mu_{2 i}=\overline{\mathbf{z}}_{i}^{\prime} \psi+b_{2 i}$, where $b_{2 i} \mid \mathbf{z}_{i} \sim \mathcal{N}\left(0, \sigma_{b_{2}}^{2}\right)$ and $\mathbf{z}_{i} \equiv\left(\mathbf{z}_{1 i t}^{\prime}, \mathbf{z}_{2 i t}^{\prime}\right)^{\prime} \equiv\left(\mathbf{z}_{i 1}^{\prime}, \mathbf{z}_{i 2}^{\prime}, \ldots, \mathbf{z}_{i T}^{\prime}\right)^{\prime}$ is a vector of all strictly exogenous variables in all time periods. Plugging this into Equation 6 gives

$$
a_{2 i t}=\mathbf{z}_{1 i t}^{\prime} \alpha_{1}+\mathbf{z}_{2 i t}^{\prime} \alpha_{2}+\overline{\mathbf{z}}_{i}^{\prime} \psi+\lambda_{2 t}+\nu_{2 i t},
$$

where $\nu_{2 \mathrm{it}}=b_{2 i}+u_{2 \mathrm{it}}$ is the new composite error term. It is well known that the coefficients on the time-varying covariates in Equation 7 are numerically equivalent to the linear fixed-effects model, making this a very robust specification (Wooldridge, 2010, p. 332).

Following Rivers and Vuong (1988) and Giles and Murtazashvili (2013), joint normality of $\left(u_{1 i t}, u_{2 i t}\right)$ conditional on $\mathbf{z}_{i}$ with $\operatorname{var}\left(u_{1 i t}\right)=1, \operatorname{cov}\left(u_{1 i t}, u_{2 i t}\right)=\tau$, and $\operatorname{var}\left(u_{2 i t}\right)=\sigma_{u_{2}}^{2}$ implies that we can rewrite our model of interest as

$$
c_{1 i t}^{*}=\mathbf{z}_{1 i t}^{\prime} \beta_{1}+\beta_{2} a_{2 i t}+\mathbf{h}_{1 i, t-1}^{\prime} \rho+\left(a_{2 i t} \times \mathbf{h}_{1 i, t-1}\right)^{\prime} \gamma+\mu_{1 i}+\lambda_{1 t}+\omega u_{2 i t}+\varepsilon_{1 i t},
$$

where we define $\omega=\tau / \sigma_{u_{2}}$.

Note that $u_{1 i t}=\omega u_{2 i t}+\varepsilon_{1 i t}=\omega\left(\nu_{2 i t}-b_{2 i}\right)+\varepsilon_{1 i t}$, so our equation of interest is contaminated by both the first-stage errors and the associated unobserved heterogeneity. The role of $\nu_{2 i t}$ is to "correct" for the contemporaneous endogeneity between the two equations, while $b_{2 i}$ allows for feedback from the unobserved effect in the reduced form.

Let $b_{1 i}=\mu_{1 i}-\omega b_{2 i}=\mu_{1 i}-\omega\left(\nu_{2 i t}-u_{2 i t}\right)$ be the composite unobserved effect and note that this does not depend on $t$ because $\nu_{2 i t}=b_{2 i}+u_{2 i t}$ by definition. Then the key question in nonlinear dynamic models is: What assumptions do we make about how the composite heterogeneity relates to the initial conditions $\mathbf{h}_{i 0}$, the covariates $\mathbf{z}_{i}$, and the reducedform errors in all periods $\nu_{2 i}$ ?

Assuming that the heterogeneity only relates to the reduced-form errors gives rise to a random-effects specification with Mundlak terms for the first-stage residuals. Assuming that the composite heterogeneity is a linear function of all three gives rise to a dynamic correlated random-effects approach. The initial conditions are not ignorable and have repercussion towards how flexibly we must treat the unobserved heterogeneity (Wooldridge, 2005a). In our case, some unobserved covariate of conflict is likely to be correlated with whether a country was initially in conflict or peace, so that independence of $\mathbf{h}_{i 0}$ and $\mathbf{z}_{i}$ is unlikely.

Following Giles and Murtazashvili (2013), we assume that $b_{1 i} \mid \mathbf{z}_{i}, \mathbf{h}_{i 0}, \nu_{2 i} \sim \mathcal{N}\left(\mathbf{z}_{i}^{\prime} \delta_{0}+\mathbf{h}_{i 0}^{\prime} \delta_{1}+\nu_{2 i}^{\prime} \delta_{3}, \sigma_{d}^{2}\right)$. This homoskedastic normal distribution implies that the composite heterogeneity is a linear function: $b_{1 i}=\mathbf{z}_{i}^{\prime} \delta_{0}+\mathbf{h}_{i 0}^{\prime} \delta_{1}+$ $\nu_{2 i}^{\prime} \delta_{3}+d_{1 i}$, where $d_{1 i} \mid \mathbf{z}_{i}, \mathbf{h}_{i 0}, \nu_{2 i} \sim \mathcal{N}\left(0, \sigma_{d}^{2}\right)$. Plugging this into Equation 8 gives the final equation:

$$
\begin{aligned}
c_{1 i t}^{*}= & \mathbf{z}_{1 i t}^{\prime} \beta_{1}+\beta_{2} a_{2 i t}+\mathbf{h}_{1 i, t-1}^{\prime} \rho+\left(a_{2 i t} \times \mathbf{h}_{1 i, t-1}\right)^{\prime} \gamma+\omega \nu_{2 i t} \\
& +\lambda_{1 t}+\mathbf{z}_{i}^{\prime} \delta_{0}+\mathbf{h}_{i 0}^{\prime} \delta_{1}+\nu_{2 i}^{\prime} \delta_{3}+d_{1 i}+\varepsilon_{1 i t},
\end{aligned}
$$

which can be estimated by standard random effects ordered probit along with the cut points $\alpha_{j}$ that will result in scaled parameters (e.g., $\beta_{1} / \sqrt{\left(1+\sigma_{d_{1}}^{2}\right)}$ and so on, assuming the usual normalization of $\operatorname{var}\left(\varepsilon_{1 i t}\right)=1$ is applied).

If the instrument were observed as is, then this approach would imply a two-step estimator. Here we implement this estimator in three steps: (i) we first generate the instrument from bilateral regressions as described below; (ii) we then estimate the reduced form given in Equation 7, obtain an estimate of the residuals $\left(\hat{\nu}_{2 i t}\right)$ and the reduced-form errors in all periods $\left(\hat{\nu}_{2 i}\right)$, and then (iii) plug these into Equation 9. The standard errors are bootstrapped over all three steps to account for the generation of the instrument and the subsequent estimation of the residuals in the first step. Note that the CF approach-in contrast to IV methods-does not require squares and interactions of instruments, making it somewhat less robust but potentially much more efficient (Wooldridge, 2010, p. 128).

In our case $T$ is moderately large, which has two implications. First, adding a new time-varying control variable means adding $T$ additional regressors. Second, the initial conditions problem is not likely to be severe. Rabe-Hesketh 
and Skrondal (2013) provided simulation results for different ways of specifying the conditional density of the unobserved effect in the dynamic binary probit model. Inspired by their study, we experimented with constraints that can be placed on the two sequences $\mathbf{z}_{i}$ and $\hat{\nu}_{2 i}$. Our results suggest that allowing only the first few periods to have an independent effect and constraining the rest to the time averages yields results that are almost indistinguishable from the full model. ${ }^{7}$

The average partial effects (APEs) are derivatives of the expectation of our specification with respect to the distribution of $b_{1 i}$ (Wooldridge, 2005b). The APEs can be different for each $t$. We usually average across all observations to obtain a single estimate.

\section{3 | Identification}

We use political fractionalization in donor countries interacted with the probability of receiving aid as our primary source of exogenous variation at the donor-recipient level. Dreher and Langlotz (2020) show that government fractionalization interacted with this probability is a strong instrument for bilateral aid. Government fractionalization is defined as the probability that any two randomly chosen deputies of the parties forming the government represent different parties (T. Beck et al. 2001). Fractionalized governments require coalitions to govern, which leads to higher expenditures through logrolling (favors) in the budgeting process, including higher foreign aid budgets and subsequent disbursements (Dreher \& Fuchs, 2011; Dreher \& Langlotz, 2020).

Most studies analyzing the effects of political fractionalization on government spending focus on parliamentary systems with proportional representation. This is because coalition governments are more likely to be generated by some systems rather than others. Electoral rules, in particular first-past-the-post (FPTP) rules, define whether government can be fractionalized at all or if there is a single-party government which negotiates the budget process in some form of reconciliation process with the legislative body. Persson, Roland, and Tabellini (2007) presented a model along these lines where majoritarian elections usually led to single-party government and less spending in equilibrium than proportional elections. Hence we prefer government fractionalization over fractionalization of the legislature as an instrument in parliamentary systems with proportional representation. ${ }^{8}$ For the few donors with FPTP systems-that is, Canada, the UK, and the USA-we use legislative fractionalization as our preferred source of exogenous variation. ${ }^{9}$

The interaction with the probability of receiving aid then introduces variation across recipients. An interaction of this endogenous probability with an exogenous variable is itself exogenous, provided we include country and time fixed effects. Just as in Nunn and Qian (2014), our identification strategy can be thought of as a difference-in-difference approach. We essentially compare the effects of aid induced by changes in political fractionalization in donor countries among regular and irregular aid recipients. We later also examine the parallel trends assumption inherent in our approach.

Applying this in a bilateral setting requires aggregating the bilateral variation in the instruments to the recipientyear level. We opt for a regression approach in which we predict aid bilaterally from the best linear combination of the two interacted instruments and then aggregate the bilateral predictions. Specifically, we predict aid from donor $j$ to recipient $i$ in year $t$ using the following regression:

$$
a_{3 i j t}=\theta_{0} g_{3 j t}+\theta_{1}\left(g_{3 j t} \times \bar{p}_{3 i j}\right)+\xi_{0} l_{3 j t}+\xi_{1}\left(l_{3 j t} \times \bar{p}_{3 i j}\right)+\mu_{3 i j}+\lambda_{3 t}+\epsilon_{3 i j t},
$$

where $g_{3 j t}$ is government fractionalization, $l_{3 j t}$ legislative fractionalization and $\bar{p}_{3 i j}$ is the pairwise probability of receiving aid. As discussed above, $g_{3 j t}$ is typically zero in FPTP systems. We set all FPTP observations of $g_{3 j t}=0$ and $l_{3 j t}=0$ in non-FPTP systems, in order only to utilize the relevant political type of political heterogeneity. The time-invariant

\footnotetext{
${ }^{7}$ We conserve degrees of freedom by splitting the two vectors, so that in the case of the exogenous variables we have $\mathbf{z}_{i}^{+}=\left(\mathbf{z}_{i 1}^{\prime}, \mathbf{z}_{i 2}^{\prime}, \ldots, \mathbf{z}_{i R}^{\prime}, \overline{\mathbf{z}}_{i}^{+^{\prime}}\right)^{\prime}$, where $R<T$ and $\overline{\mathbf{z}}_{i}^{+}=\frac{1}{T-R-1} \sum_{t=R+1}^{T} \mathbf{z}_{i t}$ is the time average after period $R$. The residual sequence, $\nu_{2 i}^{+}$, is computed analogously. Our results are not sensitive to the choice of $R$, as long as the first period is allowed to have its own coefficients. We typically set $R=4$. We also included $\mathbf{z}_{i 0}$ to little effect (as suggested by Rabe-Hesketh \& Skrondal, 2013).

${ }^{8}$ Legislative fractionalization is defined similarly to government fractionalization. It gives the probability of randomly picking two deputies from the legislature that belong to different parties.

${ }^{9}$ France is an interesting case as it is a mixed system with two-round runoff voting. However, both government and legislative fractionalization vary for France. In a robustness test we also treat France in the same way as Canada, the UK, and the USA without a material impact on the results.
} 
probability is defined as $\bar{p}_{3 i j}=\frac{1}{T} \sum_{t}^{T} \mathbf{1}\left[a_{3 i j t}>0\right]$, so that it contains the fraction of years in which recipient $i$ received a positive amount of aid from donor $j$. We again added subscripts to indicate that this equation (3) precedes the others with index (2) and (1). We do not need to control for the endogenous level of $\bar{p}_{3 i j}$ as it is captured by the recipient-donor fixed effects, $\mu_{3 i j}$. We then aggregate the predicted bilateral aid from Equation 10 across all donors in order to get predicted aid as a share of GDP at the recipient-year level. Hence $\hat{a}_{2 i t}=\sum_{j} \hat{a}_{3 i j t}$ is the instrument in Equation 7.

We may worry about what variation actually ends up in our constructed instrument. To be clear, it consists of three different components: (i) the estimated donor-recipient fixed effects aggregated over all donors, or $\sum_{j} \hat{\mu}_{3 i j}$; (ii) the estimated effects of those donor characteristics that do not vary across recipients and the time dummies aggregated over all donors, or $\sum_{j} \hat{\theta}_{0} g_{3 j t}+\sum_{j} \hat{\xi}_{0} l_{3 j t}+J \hat{\lambda}_{3 t}$; and, finally, (iii) the exogenous variation introduced by the two interaction terms aggregated over all donors, or $\sum_{j} \hat{\theta}_{1}\left(g_{3 j t} \times \bar{p}_{3 i j}\right)+\sum_{j} \hat{\xi}_{1}\left(l_{3 j t} \times \bar{p}_{3 i j}\right)$. The first two are potentially endogenous, but we control for their influence in the estimation that follows. Donor fractionalization is the same across all recipients and will be swept out by the fixed effects (or time averages) in the reduced-form equation. Similarly, everything but the interaction terms will be swept out by the recipient effects and time effects.

\section{4 | RESULTS}

\section{1 | Bilateral estimation}

We begin by briefly discussing the bilateral regression that we use to construct the instrument. Recall that we regress aid received by each recipient from a particular donor on political fractionalization, its interaction with the probability of receiving aid, and a full set of country and time fixed effects. We estimate these models with the fraction of aid in GDP as the dependent variable (not in logs, since negative flows occur when loan repayments exceed new inflows). ${ }^{10}$

The regression is estimated over 4,116 bilateral donor-recipient relations for which we have data, yielding a total of 129,348 observations. ${ }^{11}$ These results are not causal. They only serve to "translate" the exogenous variation in donor characteristics into changes in aid disbursements at the recipient level, depending on how strongly a particular recipient depends on aid from a particular donor.

The estimated coefficients of our variables of interest are as follows (standard errors accounting for bilateral correlation at the donor-recipient level are reported in parentheses below the coefficients):

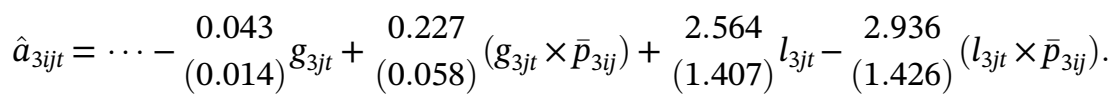

The coefficients on the interaction terms are highly significant. ${ }^{12}$ Note that the negative sign on the second interaction coefficient is misleading. In both cases, increasing political fractionalization leads to more aid disbursements for nearly all of the sample. There is interesting heterogeneity across political systems. Fractionalized parliamentary systems give more aid to regular recipients, whereas divided majoritarian systems give more aid to irregular recipients.

The effects of political fractionalization are not as large as a cursory glance at the coefficients may suggest. To see this, consider a 10-percentage-point increase of political fractionalization in a donor country when a recipient receives aid about two thirds of the time. Equation 11 predicts that this increases the aid to GDP ratio by about 0.01 percentage points for aid from proportional systems $(0.1 \times[-0.043+0.227 \times 2 / 3] \approx 0.01)$ and about 0.06 percentage points for aid from majoritarian systems $(0.1 \times[2.564-2.936 \times 2 / 3] \approx 0.06)$. The increase in majoritarian systems tends to be larger, in part because it is estimated based solely on three of the biggest donors. The cluster-robust $F$-statistic of the interaction terms is about 10.83. Note that the constructed instrument will turn out to be considerably stronger once we aggregate to the recipient (country) level. We essentially add up many small changes in the predicted aid to GDP ratio in any given year. ${ }^{13}$

\footnotetext{
${ }^{10}$ Negative flows also prevent us from using Poisson pseudo maximum likelihood models commonly used for estimating gravity equations.

${ }^{11} \mathrm{We}$ do not constrain this estimation to the balanced sample to arrive at the best possible estimate of this relationship.

${ }^{12}$ Clustering at the recipient level yields very similar results. Since we only have 28 donors, the standard errors widen noticeably when we cluster at the donor level or donor and recipient level.

${ }^{13}$ We repeated this estimation using net aid including other official flows. The results are qualitatively and statistically similar (not reported, available on request).
} 


\section{2 | Reduced form of aid}

We now turn to country-level estimates of the first-stage relationship. Table 2 shows three reduced-form regressions for aid to GDP, which we obtain by estimating the equivalent fixed-effects model of Equation 7. The residuals from these models are used as control functions in the main specifications which we estimate further below. The sample is now balanced at $T=36$ (minus the initial period) and $N=125$. This constitutes a much larger sample relative to the typical study in this field which often focuses exclusively on sub-Saharan Africa or loses observations due to the inclusion of many controls. Our data contain countries experiencing some of the most severe and longest running civil conflicts (e.g., Afghanistan, Iraq, Pakistan, and many more). Generated regressors deliver consistent estimates but inference depends on the uncertainty introduced in the bilateral stage, which is why we compute bootstrap standard errors (i.e., by sampling over recipients in the bilateral stage, generating the instrument in each iteration, aggregating to a country-year panel, and then estimating the first stage).

Two things stand out in Table 2. First, the coefficients on the instruments in all columns are estimated to be larger than one. Depending on the specification, a 1-percentage-point increase in the predicted aid to GDP ratio leads to about a 1.3-percentage-point increase in actual aid to GDP. Adding other controls moves the estimates a bit closer to unity. Including heterogeneous linear trends for each initial conflict state changes the results only marginally. The coefficient on the instrument has a straightforward interpretation. If the constructed instrument overpredicts the quantity in question, then the coefficient will be below unity, and vice versa. Not surprisingly, our aggregation of predicted bilateral flows tends to undershoot actual aid to GDP ratios and therefore has a multiplier above unity. Second, the aggregated instrument is highly relevant. The $F$-statistics based on the bootstrapped covariance matrix always exceed the conventional level of about 10 by an order of magnitude (which is also not unusual in comparable applications). ${ }^{14}$ Our instrument does not draw its power from any one donor or recipient, ${ }^{15}$ or settings where many donors are active at the same time. $^{16}$

A number of other concerns could be raised regarding the strength and validity of our identification strategy. Fractionalized governments and legislatures could be giving more aid to countries that are politically closer, more open to trade or that receive a lot of foreign direct investment. Any (conditional) correlation of our instrument with these variables might weaken the strength of our instrument and could violate the exclusion restriction in some circumstances. However, note that a violation of the exclusion restriction requires not only that fractionalization-induced aid disbursements vary in tandem with other variables and that these variables determine conflict, it also requires that these other variables have heterogeneous effects on regular and irregular aid recipients. ${ }^{17}$

\section{3 | Baseline results}

Our main specifications only include a limited set of controls but always allow for (fixed) unobserved country heterogeneity, as well as unobserved time effects, and always include the control function residuals. All of these three measures take care of omitted variables and contemporaneous endogeneity. We present two sets of estimates for our baseline results. Table 3 reports the regression results and Table 4 shows the associated average partial effects of aid on the different transition probabilities.

Consider the regressions in Table 3 first. Column (1) shows the estimates without additional controls, column (2) controls for GDP and population, and the last column includes heterogeneous trends depending on the initial conflict state (by controlling for $t \times \mathbf{h}_{i 0}$ ). The results are interesting in a couple of respects. The coefficients of aid to GDP and its interactions with the lagged states are very similar across all three specifications. The regressions suggest (i) that

\footnotetext{
${ }^{14}$ Without added controls Frankel and Romer (1999) report an F-statistic of 98.01 for their predicted trade shares.

${ }^{15}$ In Figure C-1 and Figure C-2 in the Supporting Information, we drop each donor and recipient one at a time in the bilateral sample, aggregate the data to the country level, and rerun the first-stage regression, ignoring the uncertainty from the bilateral stage. The estimates vary only within a narrow band.

${ }^{16}$ The variation of aid induced by changes in divided donor governments is likely to be higher for recipients with many active donors. To investigate this, we measure donor fragmentation by a Herfindahl index and the combined share of the three largest donors. We then interact predicted aid to GDP with a dummy indicating whether the recipient has a higher donor fragmentation than the sample mean. The coefficients on predicted aid to GDP and the first-stage $F$-statistics are qualitatively similar to those reported here. The interaction term is always insignificant.

${ }^{17}$ Table C-1 in the Supporting Information reports results with controls for voting alignment in the United Nation's General Assembly, trade openness, and FDI inflows. The first-stage estimates remain highly significant and within the range of those presented in Table 2.
} 
T A B L E 2 First-stage regressions with generated IV

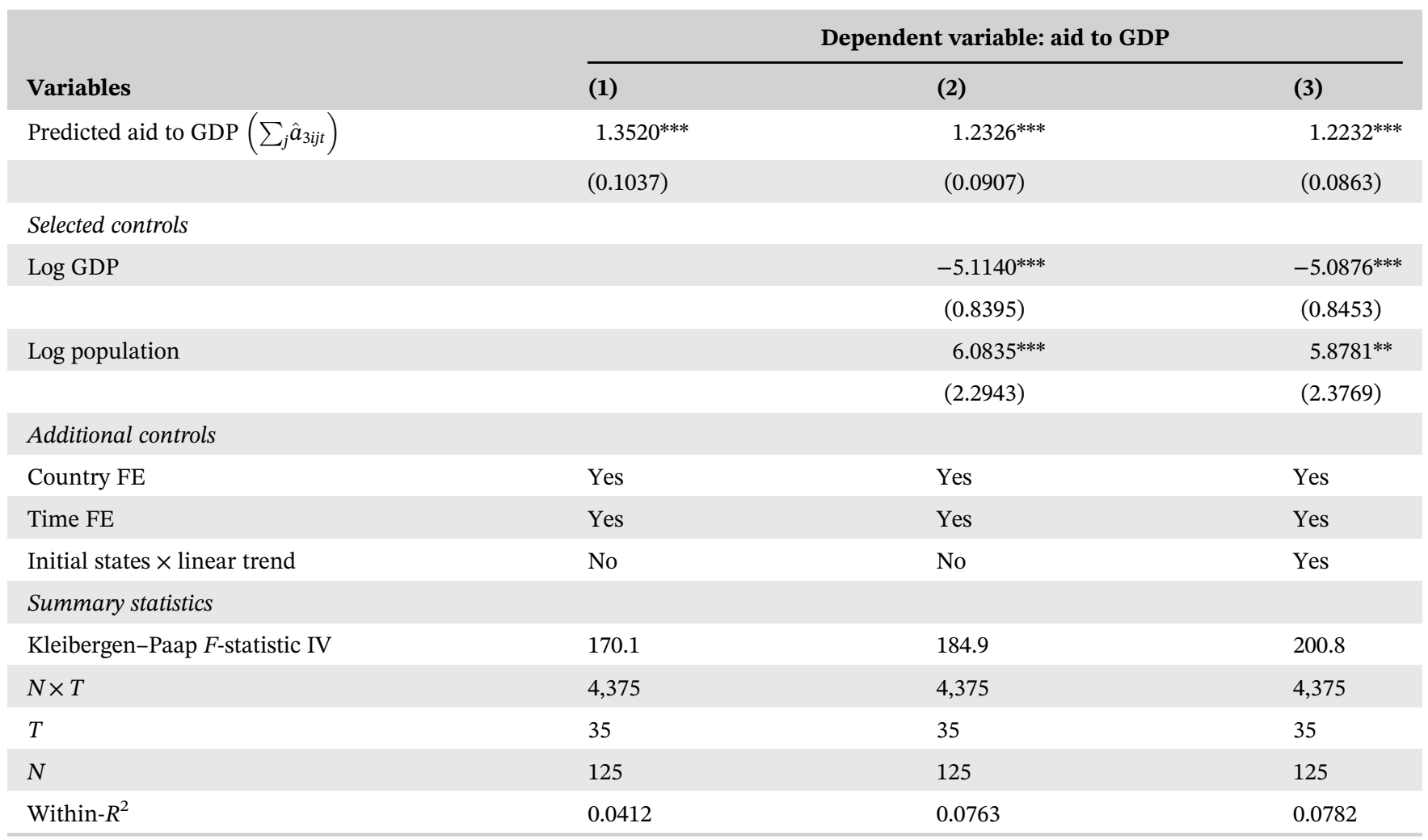

Note. The table shows the results of first-stage regressions using a linear two-way fixed-effects model. The instrument is the sum of predicted bilateral aid over all donors $\left(\sum_{j} \hat{a}_{3 i j t}\right)$ from Equation 11. Two-step panel bootstrap standard errors-sampling over recipients in the bilateral sample and computed with 999 replications-are in parentheses. ${ }^{*} p<0.1,{ }^{* *} p<0.05,{ }^{* * *} p<0.01$.

the intensifying effect of aid on conflict is stronger if the country experienced a small conflict in the year before, and (ii) that the effect is not statistically different from the base level (i.e., peace in the previous year) for the two higher conflict intensities. We also find reasonably strong evidence suggesting that aid is endogenous. The residuals from the first stage have the opposite signs and similar magnitudes to the coefficients on the base level. This suggests that we would find no evidence of an effect of aid on conflict without correcting for endogeneity (and this is indeed the case). In control function methods, testing the null that the coefficient on the residuals is zero corresponds to a Hausman test of endogeneity which does not depend on the bilateral or first stage. The reported bootstrap standard errors will therefore be on the conservative side. Nevertheless, we can always reject the null of no endogeneity at the $5 \%$ or $10 \%$ significance level.

We prefer column (2) since it accounts for scale effects (conflicts with more battle-related deaths occur in larger countries) and measures the net effect of higher aid intensity at a given income level. One might argue that this introduces a bad control issue. However, none of the coefficients on the selected time varying controls is significant. Given the similarity in our point coefficients between the different models, we do not consider this a major problem. Most existing studies use pooled methods which rely on between-country differences. Given that recipient-level CREs and conflict histories are included in all of our specifications, log GDP and log population do not seem to contribute much additional information. Note that we defer the discussion of the lagged states to the next subsection where we analyze the persistence and duration of conflicts at various intensities.

We have strong reasons to trust the estimates presented in Table 3. We allow for quasi-fixed effects and first-order multistate dynamics, and correct for contemporaneous heterogeneity. In theory, additional controls may help justify the identifying assumptions regarding the instrument but there is no ex ante reason to expect that our estimates are still biased. Including more variables also comes at a cost. Each additional variable consumes several degrees of freedom due to how the unobserved heterogeneity is modeled. We find some evidence in favor of different trends depending on the initial conflict state in column (3). However, these types of trends do not violate our identification assumption, as they do not differ across regular and irregular aid recipients. Allowing for them hardly changes the estimates of interest 
T A B LE 3 Three-step ordered probit regressions, CRE, and CF

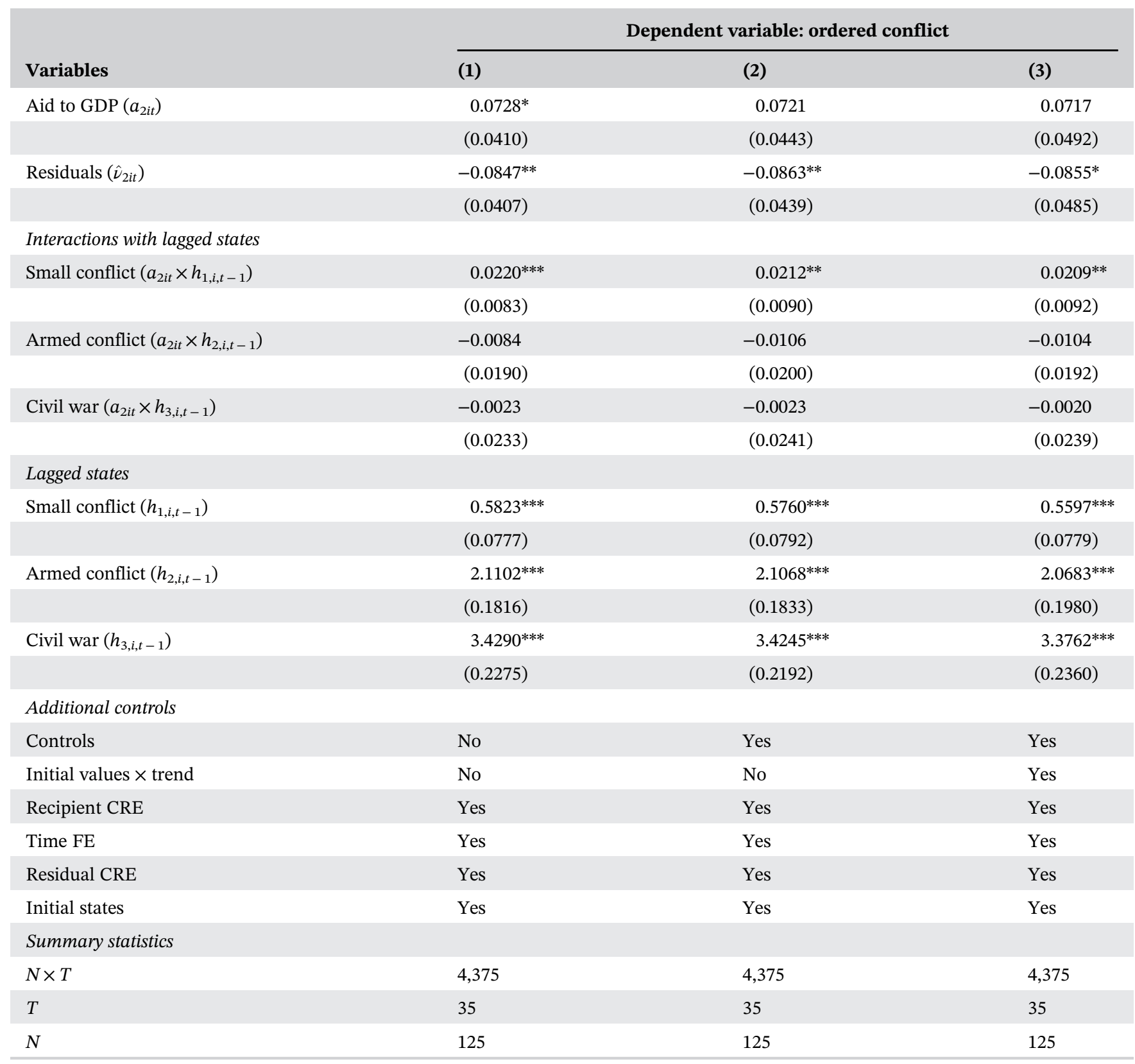

Note. The table shows the results of an ordered probit model with correlated random effects and a control function approach. Three-step panel bootstrap standard errors—sampling over recipients in the bilateral sample and computed with 999 replications-are in parentheses. All models also estimate $J$ cut points and the variance of the random recipient effect (not reported). Controls refer to the log of GDP and the $\log$ of population. ${ }^{*} p<0.10,{ }^{* *} p<0.05,{ }^{* * *} p<0.01$.

and only adds more complexity. We return to the issue of parallel trends and additional controls later when discussing extensions of the model.

To assess the magnitude of the implied effects we have to turn to partial effects as opposed to estimated coefficients. Table 4 reports estimates of the APEs for a 1-percentage-point change in aid on the various transition probabilities (see Equation 3). Note that-by definition-each row sums to zero. Although all estimates above the diagonal are positive and those below negative, we find no statistically significant evidence in favor of an effect of aid on conflict when countries are entirely at peace or engaged in an armed conflict with more than 25 BDs.

Aid has significant adverse effects in volatile environments which are not entirely peaceful but also not (yet) fully engaged in armed conflict. There, more aid makes peace less likely and a continuation of small conflict or a transition to armed conflict more likely. A 1-percentage-point increase in the ratio of foreign aid to GDP leads to an approximate 
T A B L E 4 Average partial effect of aid on transition probabilities

\begin{tabular}{|c|c|c|c|c|}
\hline From state & \multicolumn{4}{|l|}{ To state } \\
\hline \multirow[t]{2}{*}{ Peace } & -1.6333 & 1.1389 & 0.4835 & 0.0108 \\
\hline & (1.1138) & $(0.7759)$ & $(0.3402)$ & $(0.0123)$ \\
\hline Small conflict & $-2.8186^{* *}$ & $1.4175^{* *}$ & $1.3305^{* *}$ & 0.0706 \\
\hline Armed conflict & $(1.2676)$ & $(0.4808)$ & (1.1699) & $(0.5224)$ \\
\hline \multirow[t]{2}{*}{ Civil war } & -0.4252 & -0.9872 & -0.5211 & 1.9334 \\
\hline & $(0.4325)$ & $(0.7791)$ & $(0.5410)$ & $(1.5116)$ \\
\hline
\end{tabular}

Note. The table reports the average partial effect of aid on the different transition probabilities. The estimates are based on column (2) in Table 3. Three-step panel bootstrap standard errors-sampling over recipients in the bilateral sample and computed with 999 replicationsare in parentheses. Rows sum to zero. ${ }^{*} p<0.10,{ }^{* *} p<0.05,{ }^{* * *} p<0.01$.

1.4-percentage-point increase in the probability of transitioning from small conflict to armed conflict. ${ }^{18}$ The same increase in aid also significantly increases the likelihood of remaining in a small conflict (also by about 1.4 percentage points) and makes a transition to peace much less likely (by about -2.9 percentage points). ${ }^{19}$

The size of this effect is best understood in conjunction with a typical change in aid flows. The average aid-to-GDP ratio in our sample is about 5\% and the within standard deviation is also close to 5\% (when we exclude recipients who receive more than half their GDP in foreign aid-e.g., Liberia 2008, Palau 1994, 1995). Mali, for example, experienced a one standard deviation increase in its aid-to-GDP ratio in 1994 when the share of aid-to-GDP increased from about $8 \%$ to $13 \%$. At the same time, there was an escalation from small conflict to armed conflict. Consistent with this observation, our model predicts an increase in the probability of transitioning from small conflict to armed conflict of about 7 percentage points. Aid increases of this magnitude are rare. Only in about $3 \%$ of the sample did they exceed 5 percentage points, but changes around 1 percentage point are more common (about 14\% of the sample). In Uganda, for example, aid increased by about 1 percentage point on two occasions (1981 and 2002). In both cases, the country experienced an escalation of conflict.

\section{4 | Persistence, state dependence, and duration}

Table 5 shows the average transition probabilities as they are predicted by our preferred specification. The diagonal of this matrix shows the predicted persistence rates, and the off-diagonal elements are the escalation and deescalation probabilities, respectively. Note that we use persistence and continuation as synonyms, so that persistence is simply the estimated probability of remaining in a particular state. The matrix provides nearly all the terms needed to estimate state dependence as in Equation 4 apart from the weights.

We find strong evidence of state dependence in each of the four states, even after controlling for observed and unobserved heterogeneity. State dependence in armed conflict and civil war is moderately high and very similar. For both types of conflict, the sheer fact that a country finds itself in conflict implies that the probability of remaining in conflict rises by at least 30 percentage points. Comparing these estimates with the persistence probabilities shown on the diagonal is particularly instructive. State dependence accounts for the bulk of persistence in armed conflict and civil war, but much less so in small conflict and peace.

Taking a truly dynamic approach allows us to bridge another distinction that is often drawn in the conflict literature: event models versus duration models. First-order Markov models can be compared to discrete time duration

\footnotetext{
${ }^{18}$ We might be concerned that the effect of aid on the transition from small conflict to armed conflict is driven by a small subset of observations. There are about 50 switches supporting this estimate and more than 300 observations behind each of the two lower switches.

${ }^{19}$ The size of the estimated effects is also in line with recent estimates by Besley and Persson (2011b), Crost et al. (2014), and Nunn and Qian (2014). However, de Ree and Nillesen (2009) found that an increase in aid flows by $10 \%$ decreased the probability of continuation of conflict by about 8 percentage points.
} 
TABLE 5 Estimated transition probabilities and state dependence

\begin{tabular}{|c|c|c|c|c|}
\hline From state & \multicolumn{4}{|l|}{ To state } \\
\hline \multirow[t]{2}{*}{ Peace } & $79.9540^{* * *}$ & $16.3445^{* * *}$ & $3.6569^{* * *}$ & $0.0447^{*}$ \\
\hline & (1.9269) & (1.4555) & $(0.7171)$ & $(0.0258)$ \\
\hline Small Conflict & $61.7511^{* * *}$ & $27.4629^{* * *}$ & $10.4962^{* * *}$ & $0.2899 * *$ \\
\hline \multirow[t]{2}{*}{ Armed conflict } & $21.7830^{* * *}$ & $32.6899^{* * *}$ & $39.7492^{* * *}$ & $5.7778^{* * *}$ \\
\hline & $(3.8680)$ & $(2.0595)$ & $(4.3945)$ & $(1.2866)$ \\
\hline \multirow[t]{2}{*}{ Civil war } & $3.4853^{*}$ & $13.8347^{* * *}$ & $51.1025^{* * *}$ & $31.5775^{* * *}$ \\
\hline & $(1.9110)$ & $(3.0426)$ & $(3.5621)$ & $(4.3390)$ \\
\hline State dependence & $40.7941^{* * *}$ & $8.8896^{* * *}$ & $32.3801^{* * *}$ & $30.7649^{* * *}$ \\
\hline
\end{tabular}

Note. The table reports the estimated transition probabilities and state dependence. The estimates are based on column (2) in Table 3 . Three-step panel bootstrap standard errors—sampling over recipients in the bilateral sample and computed with 999 replications-are in parentheses. The upper four rows sum to $100 \%{ }^{*} p<0.10,{ }^{* *} p<0.05,{ }^{* * *} p<0.01$.

models with a constant hazard rate (e.g., Cappellari \& Jenkins, 2004). ${ }^{20}$ The expected duration of peace is about 5 years. Most conflicts are relatively short lived on average. Small conflicts last about 1.4 years, armed conflict about 1.7 years, and civil wars about 1.5 years. We are predicting conflicts that last longer than 3 years only after about the 95th percentile (and longer than 5 years after the 99th percentile). This may seem short compared to other findings in the literature but it is worth bearing in mind that we distinguish between different types of conflict that are often lumped together. A conflict cycle that goes from small over armed conflict to outright civil war and back is perfectly compatible with the duration typically found in the literature (e.g., Collier \& Hoeffler, 2004).

\section{5 | Serial correlation in $\varepsilon_{1 i t}$}

In deriving Equation 9, we assumed dynamic completeness, which implies that $\varepsilon_{1 i t}$ and, by extension, $u_{1 i t}$ are serially uncorrelated. Recall that $u_{1 i t}=\omega u_{2 i t}+\varepsilon_{1 i t}=\omega\left(\nu_{2 i t}-b_{2 i}\right)+\varepsilon_{1 i t}$. Any serial correlation in the control function errors, $\nu_{2 i t}$, will therefore spill over into the main equation and violate this assumption. ${ }^{21}$

This has two implications. First, applications of the proposed estimation approach should test for serial correlation in the first-stage residuals by regressing $\hat{\nu}_{2 i t}$ on $\hat{\nu}_{2 i, t-1}$ (without a constant) and report the corresponding results. Second, if the null of no serial correlation is rejected, then Equation 9 must be modified appropriately. We follow Giles and Murtazashvili (2013) by swapping $\nu_{2 i t}$ for $\nu_{2 i t}^{*}=\nu_{2 i t}-Q \nu_{2 i, t-1}$ in $t>1$ and $\nu_{2 i 1}^{*}=\left(1-Q^{2}\right)^{\frac{1}{2}} \nu_{2 i 1}$ in the first period. The Cochrane-Orcutt adjustment eliminates the remaining serial correlation in the first-stage errors, while the Prais-Winsten adjustment preserves the first period. The APEs, state dependence, and transition probabilities are then specified in terms of $\hat{\nu}_{2 i t}^{*}$.

Table 6 reports the corresponding results. We find strong evidence of serial correlation. Using the same data from column (2) of Table 3, a regression of the first-stage residuals on lagged values yields a coefficient of about 0.6 with a cluster-robust $t$-statistic of 9.16. The subsequent correction for serial correlation, however, only has a limited impact on our main findings. The interaction of the small conflict with aid $\left(a_{2 i t} \times h_{1, i, t-1}\right)$ is still highly significant and of comparable size. There is one noticeable change. We no longer observe a strong correction of the level effect of aid by including the control function residuals. ${ }^{22}$

\footnotetext{
${ }^{20}$ To see the equivalence, recall that the hazard rate is the probability that the current state will end, or $\operatorname{Pr}\left(T_{i}=t \mid T_{i} \geq t\right)$. The probability of exiting a particular state is geometrically distributed with $\operatorname{Pr}\left[T_{i}=t\right]=p_{i i}^{t-1}\left(1-p_{i i}\right)$. The expected survival time in state $i$ is $\mathbb{E}\left[T_{i}\right]=1 /\left(1-p_{i i}\right)$ and the quantile function is $Q(r)=F^{-1}(r)=\ln (1-r) / \ln \left(p_{i i}\right)$ where $r$ is the percentile of interest.

${ }^{21}$ To see this, assume $u_{2 i t}=\phi u_{2 i, t-1}+e_{2 i t}$ with $\phi \neq 0$ and $\operatorname{var}\left(e_{2 i t}\right)=\sigma_{e_{2}}^{2}$. It is straightforward to show that $\operatorname{cov}\left(\varepsilon_{1 i t}, \varepsilon_{1 i, t-1}\right)=\omega^{2} \phi \operatorname{var}\left(e_{2 i t}\right)>0$ in all but the trivial case of no endogeneity $(\omega=0)$.

${ }^{22}$ Donor government fractionalization does not change every year, so that our instrument contains a lot of serial correlation by construction. The wider standard error on the level effect of aid also spills over into the estimation of other terms in the APE matrix.
} 
T A B L E 6 Correcting for serial correlation

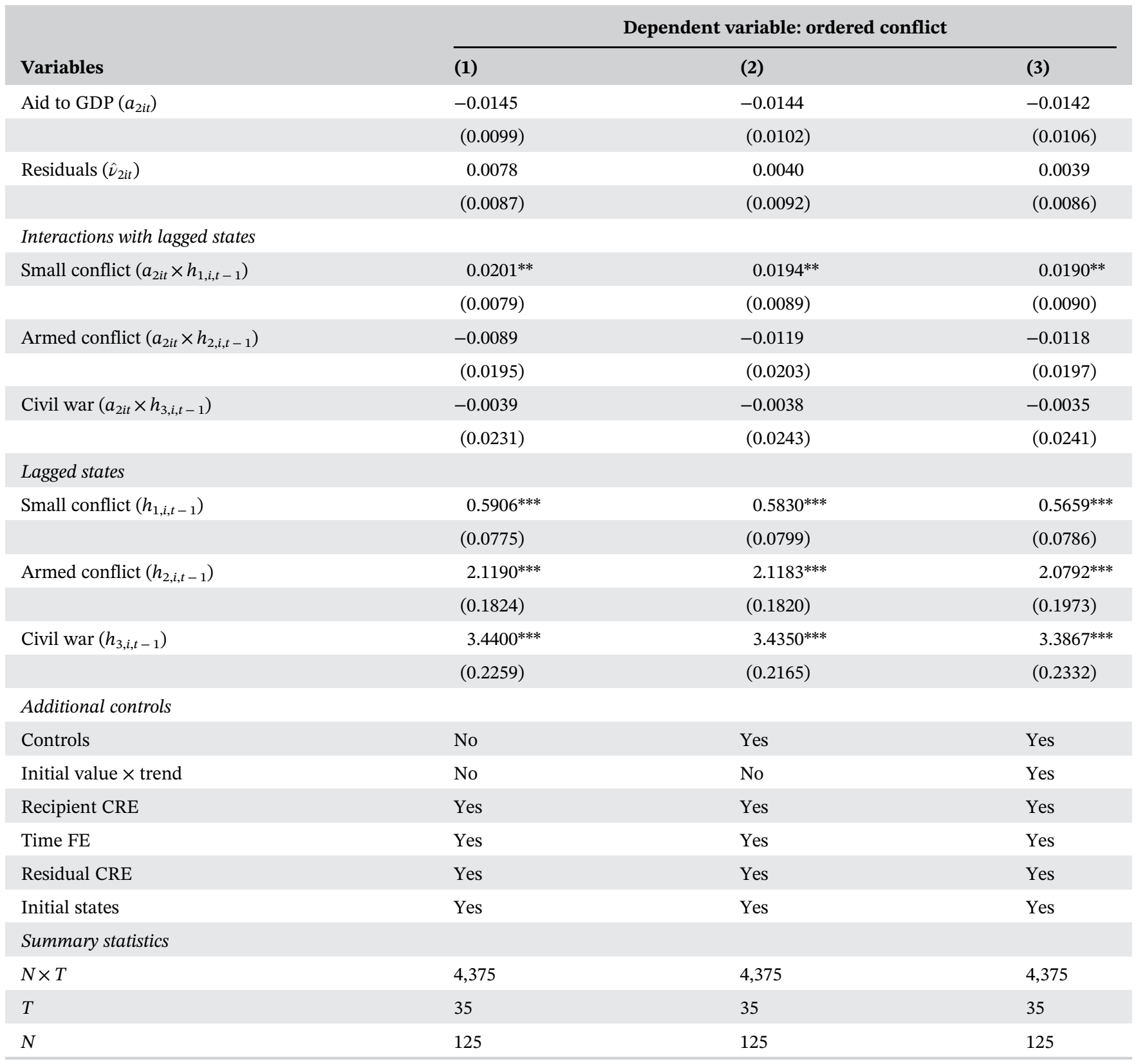

Note. The table shows the results of an ordered probit model with correlated random effects and a control function approach with a correction for serial correlation in the reduced-form errors. Three-step panel bootstrap standard errors-sampling over recipients in the bilateral sample and computed with 999 replications-are in parentheses. All models also estimate $J$ cut points and the variance of the random recipient effect (not reported). Controls refer to the log of GDP and the log of population. ${ }^{*} p<0.10,{ }^{* *} p<0.05,{ }^{* * *} p<0.01$.

\subsection{Identification assumptions and falsification}

Our local average partial effect compares the effects of politically induced differences in bilateral aid between regular and irregular aid recipients. This raises the question of whether the parallel trends assumption inherent in differencein-difference approaches is satisfied, or if spurious nonlinear trends are at work. Our identification strategy would be invalid if the time-varying component of our instrument is spuriously correlated with the time trend in conflict and the strength of this time trend depends on the regularity of aid receipts. ${ }^{23}$ Put differently, our finding that aid leads to an

\footnotetext{
${ }^{23}$ See Christian and Barrett (2017), who show that such nonlinear trends could be driving the positive effect of food aid on conflict documented in Nunn and Qian (2014).
} 

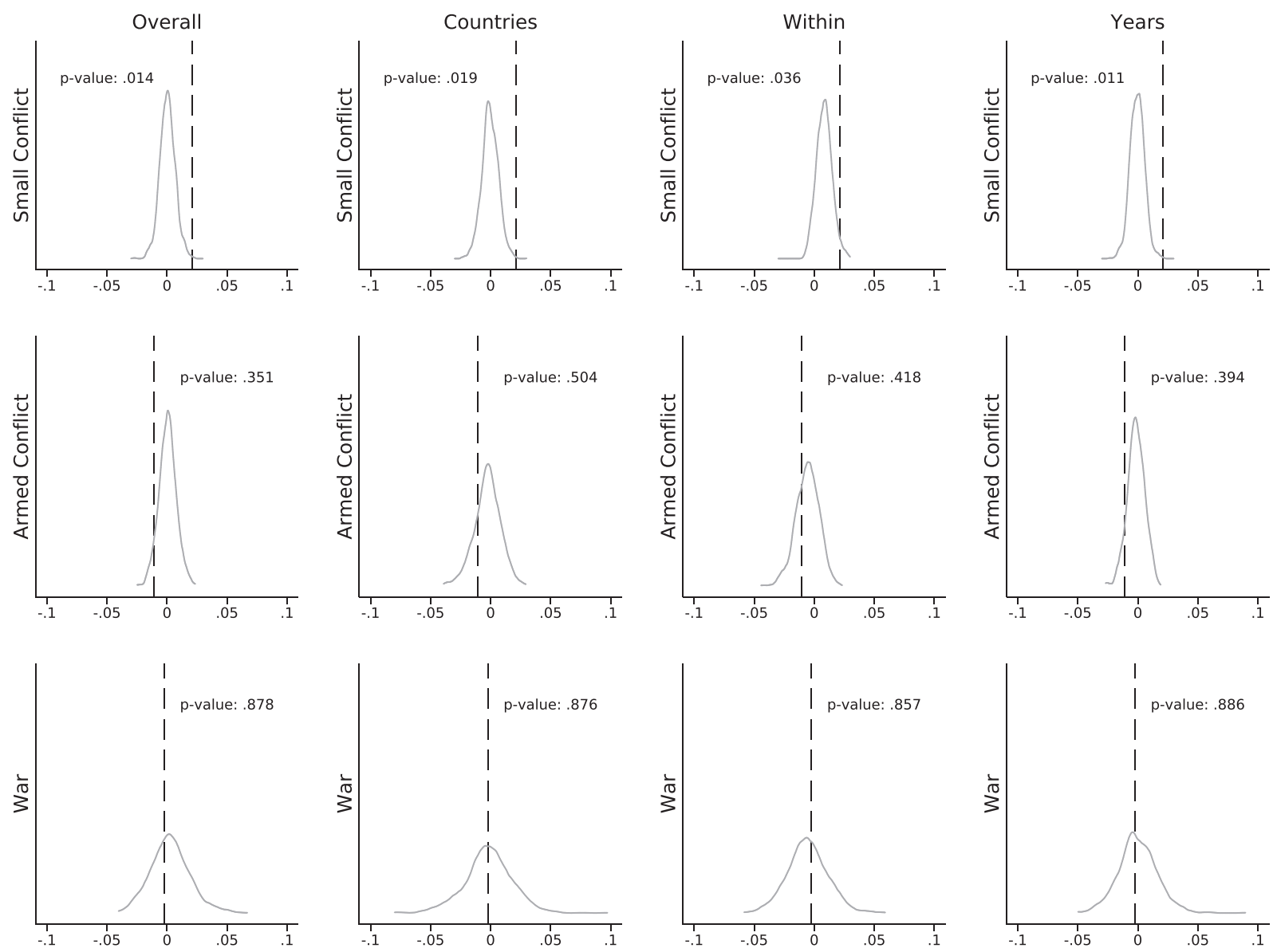

F I G U RE 2 Randomization test. The figure shows the distribution of point coefficients of our main interaction terms based on 999 Monte Carlo replications. "Overall” randomizes all observations, "Countries" entire time series between countries, "Within" years within countries, and "Years" countries within years. Dashed vertical lines indicate the original estimate from column (2) in Table 3. The $p$-values are calculated as the proportion of times that the absolute value of the $t$-statistics in the simulated data exceed the absolute value of the original $t$-statistic

escalation of conflict rests on the coincident timing of politically induced aid flows and the observed conflict histories. Randomizing aid flows along various dimensions allows us to break this temporal structure.

Figure 2 reports the results from 999 Monte Carlo simulations for four randomization strategies. We randomly reassign the aid to GDP ratio by exchanging (i) all observations in the sample-labeled Overall, (ii) the entire time series between countries-labeled Countries, (iii) years within countries-labeled Within, and (iv) countries within yearslabeled Years. For each placebo test, we report the distribution of the coefficients on the interaction terms. The $p$-values are calculated as the proportion of times that the absolute value of the $t$-statistics in the simulated data exceed the absolute value of the original $t$-statistic. The results unambiguously show that our findings are not driven by global trends, cross-sectional dependence, or selection of countries into regular aid receipts. While the original data generate a strong interaction effect of aid with the lag of small conflict, the simulations are centered on zero and very rarely include such an effect by chance.

\section{7 $\quad$ Further tests of robustness}

We run a battery of robustness checks to verify our main findings (all corresponding results are relegated to the Supporting Information and discussed there in detail). The results are robust to (i) specifying linear models to show that we are not identifying these effects by functional form only; (ii) changing the outcome variable to variants of the industry standard, which illustrates that the modeling of small conflicts is key; (iii) leaving out particular types of violence in the definition of "small conflict"; (iv) altering the definition of foreign aid; (v) adding controls in the instrument 
generation stage to account for bilateral correlations in trade and political alignments; (vi) including additional covariates, such as neighbors in conflict, in the main model; and (vii) considering the roles played by multilateral and humanitarian aid. Last but not least, we compare our findings to those presented in Nunn and Qian (2014) and present falsification tests using their instruments.

\section{5 | CONCLUSION}

This paper studies the effects of development aid on conflict. While there is a large literature on the topic, it typically separates the onset of a conflict from its continuation and neglects smaller acts of violence. This misses important dynamics which our paper makes an effort to expose. We introduce a dynamic ordered probit framework which can account for unobserved heterogeneity and endogenous variables, together with an identification strategy based on the characteristics of the electoral system of donor countries.

Our results show that the effects of bilateral aid are heterogeneous with respect to the different intensity levels of conflict. Whereas aid increases the probability that a conflict escalates from a low level of political violence to armed conflict, we find little evidence in favor of an adverse effect of aid in truly peaceful countries. Moreover, aid does not seem to affect the transition probabilities once a country experiences armed conflict or civil war. These results underline the importance of separating truly peaceful situations from countries exposed to small conflict. If we did not account for this distinction, we would fail to detect an effect of aid on conflict.

These findings call for care when devising aid policies for countries affected by conflict. Particular care has to be exercised when aid is given to countries where turmoil is already present but armed conflict has not yet erupted. Our results suggest that aid might be more harmful than helpful in these situations, despite best intentions. Finally, our analysis focuses on conflict but the empirical framework we offer could be useful in many other settings with ordered outcomes.

\section{ACKNOWLEDGEMENTS}

Open access funding enabled and organized by Projekt DEAL.

\section{OPEN RESEARCH BADGES}

\section{(II)}

This article has been awarded Open Data Badge for making publicly available the digitally-shareable data necessary to reproduce the reported results. The data is available at [http://qed.econ.queensu.ca/jae/datasets/bluhm001/]

\section{REFERENCES}

Acemoglu, D., \& Wolitzky, A. (2014). Cycles of conflict: An economic model. American Economic Review, 104(4), $1350-1367$.

Ahmed, F. Z., \& Werker, E. (2015). Aid and the rise and fall of conflict in the Muslim world. Quarterly Journal of Political Science, 10(2), $155-186$

Banks, A. S., \& Wilson, K. A. (2015). Cross-national time-series data archive. Jerusalem, Israel: Databanks International.

Bazzi, S., \& Blattman, C. (2014). Economic shocks and conflict: Evidence from commodity prices. American Economic Journal: Macroeconomics, 6(4), 1-38.

Beck, N., Katz, J. N., \& Tucker, R. (1998). Taking time seriously: Time-series-cross-section analysis with a binary dependent variable. American Journal of Political Science, 42(4), 1260-1288.

Beck, T., Clarke, G., Groff, A., Keefer, P., \& Walsh, P. (2001). New tools in comparative political economy: The database of political institutions. World Bank Economic Review, 15(1), 165-176.

Becker, G. S. (1968). Crime and punishment: An economic approach. Journal of Political Economy, 76(2), 169-217.

Berman, N., \& Couttenier, M. (2015). External shocks, internal shots: The geography of civil conflicts. Review of Economics and Statistics, 97 (4), 758-776.

Besley, T., \& Persson, T. (2011a). Fragile states and development policy. Journal of the European Economic Association, 9(3), 371-398.

Besley, T., \& Persson, T. (2011b). The logic of political violence. Quarterly Journal of Economics, 126(3), 1411-1445.

Blattman, C., \& Miguel, E. (2010). Civil war. Journal of Economic Literature, 48(1), 3-57.

Brückner, M. (2013). On the simultaneity problem in the aid and growth debate. Journal of Applied Econometrics, 28(1), 126-150.

Buenode Mesquita, E. (2013). Rebel tactics. Journal of Political Economy, 121(2), 323-357.

Cappellari, L., \& Jenkins, S. P. (2004). Modelling low income transitions. Journal of Applied Econometrics, 19(5), 593-610. 
Christian, P., \& Barrett, C. B. (2017). Revisiting the effect of food aid on conflict: A methodological caution (Policy Research Working Paper 8171). Washington, DC: World Bank.

Collier, P., \& Hoeffler, A. (2004). Greed and grievance in civil war. Oxford Economic Papers, 56(4), 563-595.

Crost, B., Felter, J., \& Johnston, P. (2014). Aid under fire: Development projects and civil conflict. American Economic Review, 104(6), 1833-1856.

de Ree, J., \& Nillesen, E. (2009). Aiding violence or peace? The impact of foreign aid on the risk of civil conflict in Sub-Saharan Africa. Journal of Development Economics, 88(2), 301-313.

Dreher, A., \& Fuchs, A. (2011). Does terror increase aid? Public Choice, 149(3-4), 337-363.

Dreher, A., \& Langlotz, S. (2020). Aid and growth: New evidence using an excludable instrument. Canadian Journal of Economics, 53(3).

Dube, O., \& Naidu, S. (2015). Bases, bullets and ballots: The effect of US military aid on political conflict in Colombia. Journal of Politics, 77(1), 249-267.

Esteban, J., Mayoral, L., \& Ray, D. (2012). Ethnicity and conflict: An empirical study. American Economic Review, 102(4), $1310-1342$.

Fearon, J. D., \& Laitin, D. D. (2003). Ethnicity, insurgency, and civil war. American Political Science Review, 97(1), 75-90.

Frankel, J. A., \& Romer, D. (1999). Does trade cause growth? American Economic Review, 89(3), 379-399.

Giles, J., \& Murtazashvili, I. (2013). A control function approach to estimating dynamic probit models with endogenous regressors. Journal of Econometric Methods, 2(1), 69-87.

Gleditsch, N. P., Wallensteen, P., Eriksson, M., Sollenberg, M., \& Strand, H. (2002). Armed conflict 1946-2001: A new dataset. Journal of Peace Research, 39(5), 615-637.

Nunn, N., \& Qian, N. (2014). US food aid and civil conflict. American Economic Review, 104(6), 1630-1666.

Persson, T., Roland, G., \& Tabellini, G. (2007). Electoral rules and government spending in parliamentary democracies. Quarterly Journal of Political Science, 2(2), 155-188.

Rabe-Hesketh, S., \& Skrondal, A. (2013). Avoiding biased versions of Wooldridge's simple solution to the initial conditions problem. Economics Letters, 120(2), 346-349.

Rivers, D., \& Vuong, Q. H. (1988). Limited information estimators and exogeneity tests for simultaneous probit models. Journal of Econometrics, 39(3), 347-366.

Rohner, D., Thoenig, M., \& Zilibotti, F. (2013). War signals: A theory of trade, trust, and conflict. Review of Economic Studies, 80(3), 1114-1147.

Wooldridge, J. M. (2005a). Simple solutions to the initial conditions problem in dynamic, nonlinear panel data models with unobserved heterogeneity. Journal of Applied Econometrics, 20(1), 39-54.

Wooldridge, J. M. (2005b). Unobserved heterogeneity and estimation of average partial effects. In D. W. K. Andrews, \& J. H. Stock (Eds.), Identification and inference for econometric models: Essays in honor of Thomas Rothenberg(pp. 27-55). Cambridge, UK: Cambridge University Press.

Wooldridge, J. M. (2010). Econometric analysis of cross section and panel data (2nd ed.). Cambridge, MA: MIT Press.

\section{SUPPORTING INFORMATION}

Additional supporting information may be found online in the Supporting Information section at the end of this article.

How to cite this article: Bluhm R, Gassebner M, Langlotz S, Schaudt P. Fueling conflict? (De)escalation and bilateral aid. J Appl Econ. 2021;36:244-261. https://doi.org/10.1002/jae.2797 